\title{
Comprehensive immunohistochemical analysis of tumor microenvironment immune status in esophageal squamous cell carcinoma
}

\author{
Ken Hatogai ${ }^{1,2,3}$, Shigehisa Kitano ${ }^{4}$, Satoshi Fujii ${ }^{1}$, Takashi Kojima ${ }^{2}$, Hiroyuki Daiko ${ }^{5}$, \\ Shogo Nomura ${ }^{6}$, Takayuki Yoshino ${ }^{2}$, Atsushi Ohtsu ${ }^{2,7}$, Yuichi Takiguchi ${ }^{3}$, Toshihiko \\ Doi $^{2}$, Atsushi Ochiai ${ }^{1}$ \\ ${ }^{1}$ Division of Pathology, Exploratory Oncology Research and Clinical Trial Center, National Cancer Center, Kashiwa, Chiba, Japan \\ ${ }^{2}$ Department of Gastroenterology and Gastrointestinal Oncology, National Cancer Center Hospital East, Kashiwa, Chiba, \\ Japan \\ ${ }^{3}$ Department of Medical Oncology, Graduate School of Medicine, Chiba University, Chuo-ku, Chiba, Japan \\ ${ }^{4}$ Department of Experimental Therapeutics, Exploratory Oncology Research and Clinical Trial Center, National Cancer Center, \\ Tokyo, Japan \\ ${ }^{5}$ Department of Esophageal Surgery, National Cancer Center Hospital East, Kashiwa, Chiba, Japan \\ ${ }^{6}$ Biostatistics Division, Center for Research Administration and Support, National Cancer Center, Kashiwa, Japan \\ ${ }^{7}$ Exploratory Oncology Research and Clinical Trial Center, National Cancer Center, Kashiwa, Japan \\ Correspondence to: Atsushi Ochiai, email: aochiai@east.ncc.go.jp
}

Keywords: esophageal cancer, immunohistochemistry, PD-L1, tumor infiltrating lymphocyte, macrophage

Received: December 31, $2015 \quad$ Accepted: June 04, $2016 \quad$ Published: June 15, 2016

\section{ABSTRACT}

Immunotherapy with anti-PD-1 antibody preliminarily showed promising efficacy for treating esophageal squamous cell carcinoma (ESCC). Herein, we used tissue microarrays and immunohistochemically analyzed PD-L1 and various tumor infiltrating immune cells (TIICs) in specimens from 196 ESCC patients who had undergone curative resection without preoperative therapy. PD-L1 expressions in tumor cells (TCs) and TIICs, as well as infiltration of lymphocytes $\left(\mathrm{CD4}^{+}, \mathrm{CDB}^{+}, \mathrm{FOXP3}^{+}\right.$, and PD- $1^{+}$) and macrophages ( $\mathrm{CD}^{+} 8^{+}$and $\mathrm{CD204}{ }^{+}$), were evaluated. PD-L1 was expressed in TCs of $18.4 \%$ and in TIICs of $83.3 \%$ of these patients. PD-L1 expressions in TCs and TIICs were associated with significant infiltration of various TIIC types, especially $\mathrm{CD8}^{+}$cells. PD-L1 expressions in both TCs and TIICs were significantly associated with favorable overall survival, and combining their levels enhanced prognostic accuracy. Prognostic impacts of PD-L1 expressions in TCs and TIICs, abundant PD-1 ${ }^{+}$cell infiltration, a high $\mathrm{CD8}^{+} / \mathrm{FOXP3}^{+}$ratio, and the $\mathrm{CD8}^{+} / \mathrm{CD204}^{+}$ratio remained significant after adjusting for clinicopathological factors. In conclusion, PD-L1 expression reflects anti-tumor immunity, and PD-1/PD-L1 expression and the ratio of infiltrating effector to immune suppressor cells have prognostic value. Therapeutic strategies inhibiting the PD-1/PD-L1 signal and immune suppressor cells are anticipated in ESCC patients.

\section{INTRODUCTION}

Squamous cell carcinoma is the predominant histological type of esophageal cancer worldwide, though the incidence of esophageal adenocarcinoma exceeds that of squamous cell carcinoma in the UK, certain other western European countries, and the United States [1]. Smoking and alcohol consumption, known as major risk factors for esophageal squamous cell carcinoma (ESCC), have synergistic effects on carcinogenesis, which are shared with head and neck and also lung cancers [2-4]. Chronic exposure to carcinogens such as nitrosamine related to smoking and the alcohol metabolite aldehyde cause DNA damage and multiple genetic changes $[5,6]$. Though no driver gene mutations have yet been detected in ESCC, among solid tumors the somatic mutation rate in ESCC is relatively high $[7,8]$. 
Recent advances in cancer immunology have revealed the importance of signaling between Programmed Death-1 (PD-1), expressed on antigen-experienced T cells, and its ligand PD-L1, expressed on antigen presenting cells and tumor cells (TCs) [9]. Anti-PD-1 or anti-PD-L1 antibodies have clinically benefitted patients with some solid cancers in early clinical trials [10-12]. In a recent phase 3 trial, a favorable response and survival outcomes were obtained with an anti-PD-1 monoclonal antibody, nivolumab, in advanced squamous-cell non-small-cell lung cancer which is genetically similar to ESCC $[13,14]$. In addition, a favorable response and durable efficacy of anti-PD-1 monoclonal antibodies for ESCC were also demonstrated in early clinical trials $[15,16]$. In the context of biomarker analysis, PD-L1 expression in TCs, that in tumor infiltrating immune cells (TIICs), and a high level of $\mathrm{CD}^{+} \mathrm{T}$ cell infiltration have been shown, in several clinical trials testing anti-PD-1 and anti-PD-L1 antibody therapy, to be potential predictive biomarkers of clinical efficacy [17-20].

PD-L1 is expressed on TCs in ESCC and other solid tumors $[21,22]$. Recently, high mutation burdens in tumors were reported to be associated with a clinical benefit of PD-1 blockade [23]. Given the relatively high mutation burden in ESCC [7, 8], PD-1/PD-L1 blockade shows promise for treating ESCC. The importance of the immune response to cancer has been studied in terms of infiltration of lymphocytes and macrophages in ESCC [24-26]. To date, no study has explored the associations of PD-L1 expressions in TCs and TIICs and the infiltration of effector cells or immune suppressor cells (regulatory $\mathrm{T}$ cells and M2 macrophages).

We performed the present immunohistochemical (IHC) study using surgically resected specimens from a large cohort of treatment-naïve patients with ESCC to identify and quantify PD-L1 expressions in tumors and their associations with anti-tumor immune responses. The survival impacts of various immunological factors were also assessed.

\section{RESULTS}

\section{PD-L1 expressions in ESCC and TIICs}

The clinicopathological characteristics of our patients are listed in Table 1. None of the patients in this study had distant organ metastasis or had received immune therapies, such as immune checkpoint inhibitors and immune cell therapy. Representative cases with PD-L1 expression in TCs and TIICs are shown in Figure 1. PD-L1 expression was positive in TCs from 36 patients (18.4\%, 95\% confidence interval [CI]: 13.2-24.5). PD-L1 expression was positive in TIICs from 119 patients $(60.7 \%, 95 \%$ CI: 53.5-67.6). Among patients showing PD-L1 positive in TCs, $83.3 \%$ demonstrated PD-L1 positive in TIICs, a significantly higher percentage than that in patients whose TCs were PD-L1 negative $(P<0.001)$ (Table 2). In total, 125 patients $(63.8 \%, 95 \%$ CI: 56.6-67.6) had TC and/or TIIC positive for PD-L1. The only clinicopathological characteristic significantly associated with PD-L1 expression status, specifically that in TCs, was age (Table 1).

\section{PD-L1 expression and infiltration of TIICs}

IHC results of representative cases with each TIIC type are shown in Supplementary Figure S1. Figure 2 demonstrates the relationship between PD-L1 expression status in TCs and TIICs and the number and ratio of each TIIC type. The numbers of all TIIC types evaluated were higher in subgroups with PD-L1 positive in TCs and in TIICs than in subgroups with PD-L1 negative in TCs and in TIICs. This tendency was especially strong for $\mathrm{CD} 8^{+}$ cells. The $\mathrm{CD}^{+} / \mathrm{FOXP}^{+}$and $\mathrm{CD}^{+} / \mathrm{CD}^{2} 04^{+}$ratios were also higher in subgroups with PD-L1 positive in TCs and in TIICs. In contrast, the $\mathrm{FOXP}^{+} / \mathrm{CD}^{+}$ratio tended to be lower, though not significantly, in subgroups with PD-L1 positive in TCs and in TIICs.

\section{Survival analyses according to immunological factors}

The median follow-up time of the censored cases was 5.5 years (range, $0.1-10.6$ ) from the date of surgery. The overall survival (OS) curves according to PD-L1 expression are presented in Figure 3. Patients with PD-L1 positive in TCs demonstrated significantly better OS than those with PD-L1 negative in TCs $(P=0.019)$. Patients with PD-L1 positive in TIICs had significantly better OS than those with PD-L1 negative in TIICs $(P=0.041)$. We divided patients into three groups according to the PD- L1 expression status of their TCs and TIICs: both PD-L1 positive (group 1), either one PD-L1 positive (group 2), and both PD-L1 negative (group 3). The separate OS curves for these 3 groups revealed a statistically significant difference only between groups 1 and $3(P=0.097$ between groups 1 and 2, $P=0.098$ between groups 2 and 3, $P=0.007$ between groups 1 and 3 ).

The OS curves according to TIIC ratios are presented in Figure 4. Patients with a high $\mathrm{CD} 8^{+} / \mathrm{FOXP}^{+}$ ratio had significantly better OS than those with a low $\mathrm{CD}^{+} / \mathrm{FOXP}^{+}$ratio $(P=0.010)$. Patients with a high $\mathrm{CD}^{+} / \mathrm{CD} 204^{+}$ratio had significantly better OS than those with a low $\mathrm{CD} 8^{+} / \mathrm{CD} 204^{+}$ratio $(P=0.024)$. In contrast, patients with a high $\mathrm{FOXP} 3^{+} / \mathrm{CD}^{+}$ratio showed significantly poorer OS than those with a low $\mathrm{FOXP}^{+} /$ $\mathrm{CD}^{+}$ratio $(P=0.036)$. Although the $\mathrm{OS}$ curves were drawn separately according to $\mathrm{CD} 204^{+} / \mathrm{CD} 68^{+}$ratios, the difference did not reach statistical significance $(P=0.314)$. Among each TIIC type assessed, prognostic significance was demonstrated in $\mathrm{CD} 8^{+}$cells $(P=0.040)$ and $\mathrm{PD}-1^{+}$ cells $(P=0.032)$ (Supplementary Figure S2). 
Table 1: Clinicopathological characteristics according to PD-L1 expressions in tumor cells and tumor infiltrating immune cells

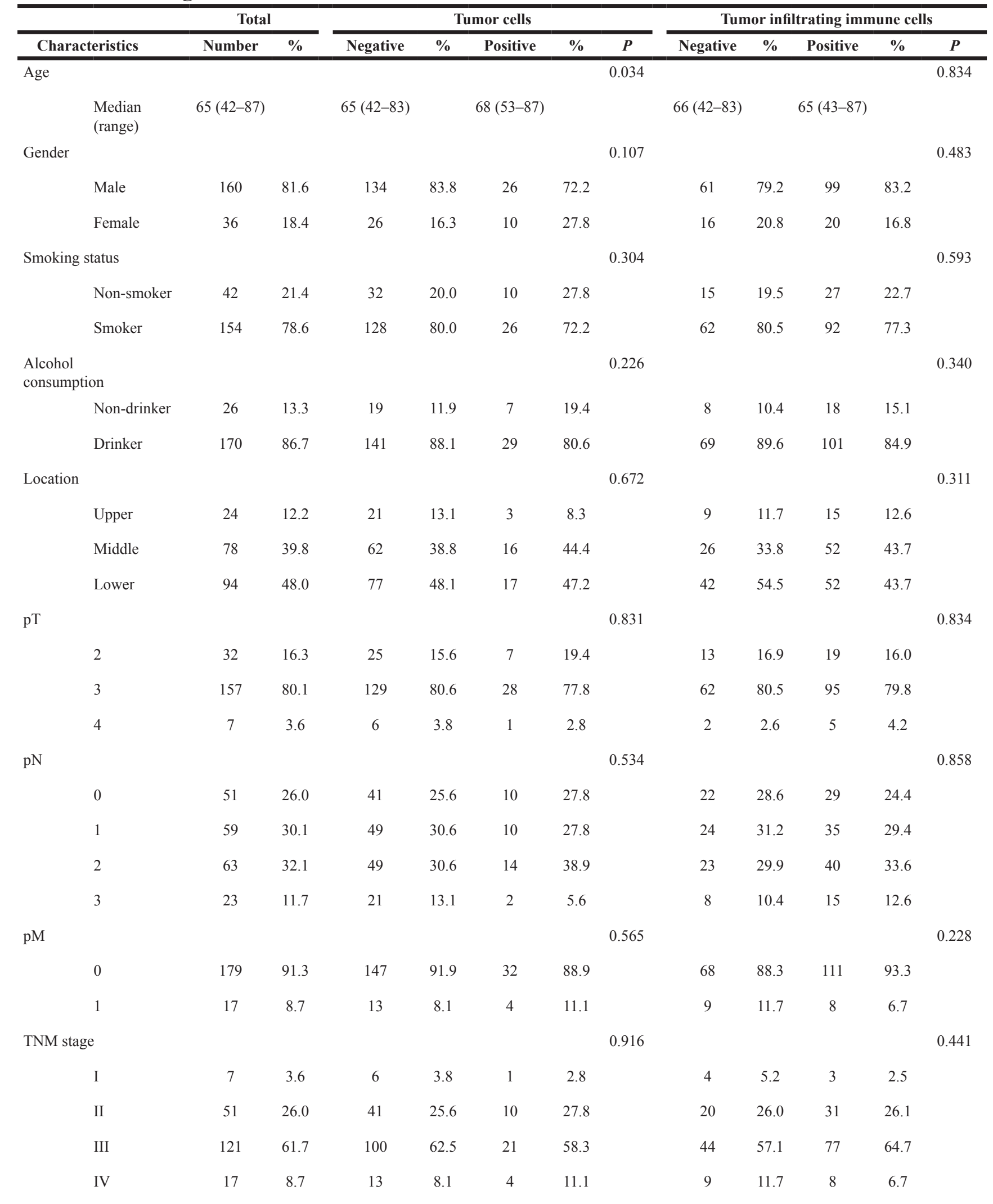


Grade

\begin{tabular}{|c|c|c|c|c|c|c|c|c|c|c|}
\hline $\mathrm{W} / \mathrm{D}$ & 48 & 24.5 & 43 & 26.9 & 5 & 13.9 & 17 & 22.1 & 31 & 26.1 \\
\hline $\mathrm{M} / \mathrm{D}$ & 127 & 64.8 & 101 & 63.1 & 26 & 72.2 & 52 & 67.5 & 75 & 63.0 \\
\hline $\mathrm{P} / \mathrm{D}$ & 21 & 10.7 & 16 & 10.0 & 5 & 13.9 & 8 & 10.4 & 13 & 10.9 \\
\hline
\end{tabular}

Lymphatic invasion

0.442

0.668

\begin{tabular}{|c|c|c|c|c|c|c|c|c|c|}
\hline Absent & 93 & 47.4 & 78 & 48.8 & 15 & 41.7 & 38 & 49.4 & 55 \\
\hline Present & 103 & 52.6 & 82 & 51.3 & 21 & 58.3 & 39 & 50.6 & 64 \\
\hline
\end{tabular}

Venous invasion

0.145

$\begin{array}{lcccccccccc}\text { Absent } & 24 & 12.2 & 17 & 10.6 & 7 & 19.4 & 7 & 9.1 & 17 & 14.3 \\ \text { Present } & 172 & 87.8 & 143 & 89.4 & 29 & 80.6 & 70 & 90.9 & 102 & 85.7\end{array}$

Abbreviations: W/D, well differentiated; M/D, moderately differentiated; P/D, poorly differentiated.
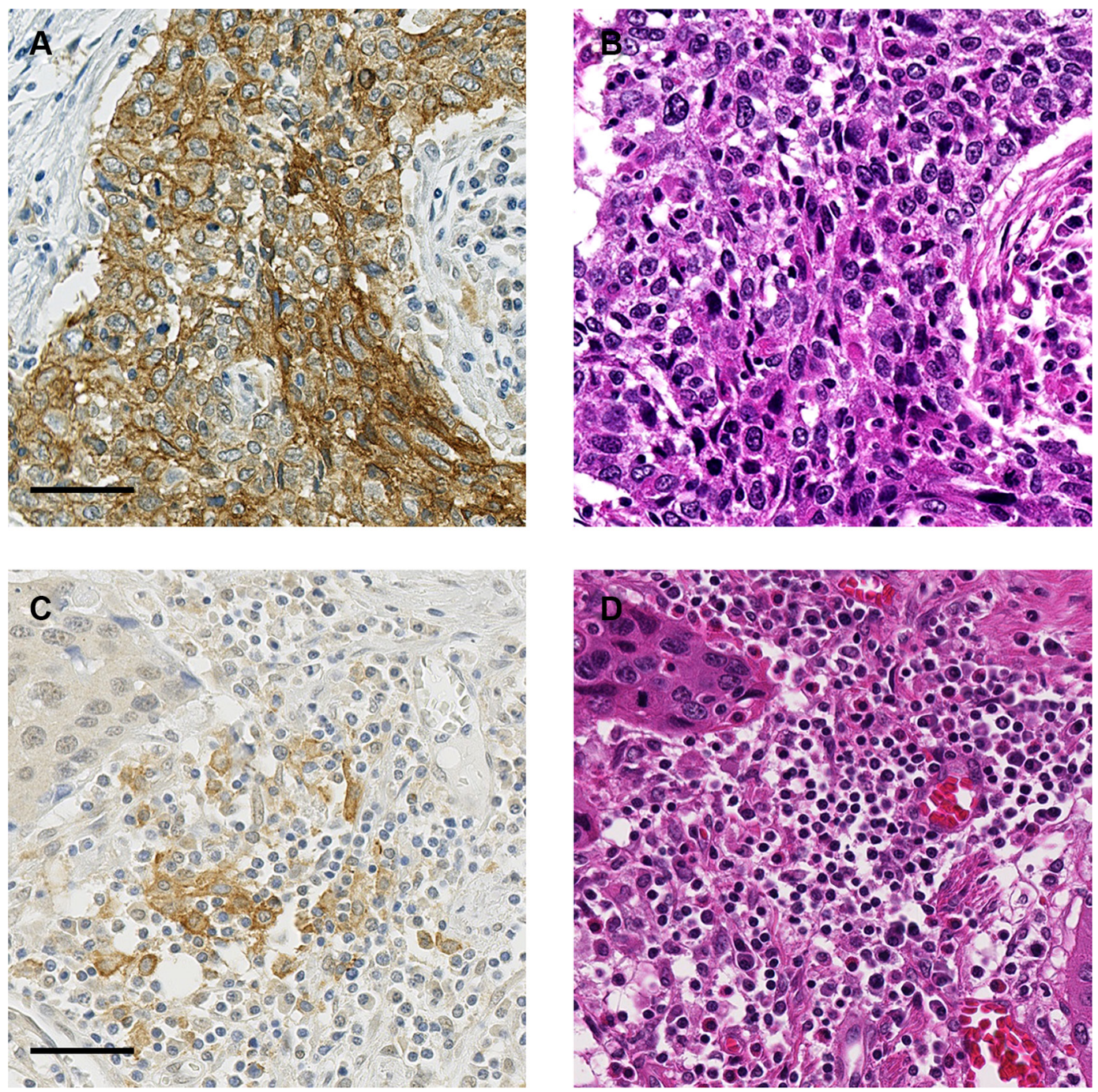

Figure 1: Representative images of PD-L1 expression. (A) TCs are positive for membranous staining of PD-L1. (B) H\&E image of the serial section in (A). (C) TIICs are positive for PD-L1. (D) H\&E image of the serial section in (C). Bar: $50 \mu \mathrm{m}$. 


\section{Multivariate analyses for survival outcomes}

The results of univariate and multivariate survival analyses are presented in Table 3. Both TCs (HR 0.461, 95\% CI: $0.246-0.864, P=0.016$ ) and TIICs (HR 0.590, 95\% CI: 0.394-0.884, $P=0.010$ ) being PD-L1 positive was significantly associated with longer OS in multivariate analysis even after adjusting for potentially confounding clinicopathological factors. A high $\mathrm{CD}^{+} / \mathrm{FOXP}^{+}$ratio (HR 0.617, 95\% CI: $0.413-0.923, P=0.019$ ) and a high $\mathrm{CD} 8^{+} / \mathrm{CD} 204^{+}$ratio (HR $0.650,95 \%$ CI: $0.439-0.962$, $P=0.031)$ were also significantly associated with longer OS, although none of the TIIC types individually showed

\section{A}

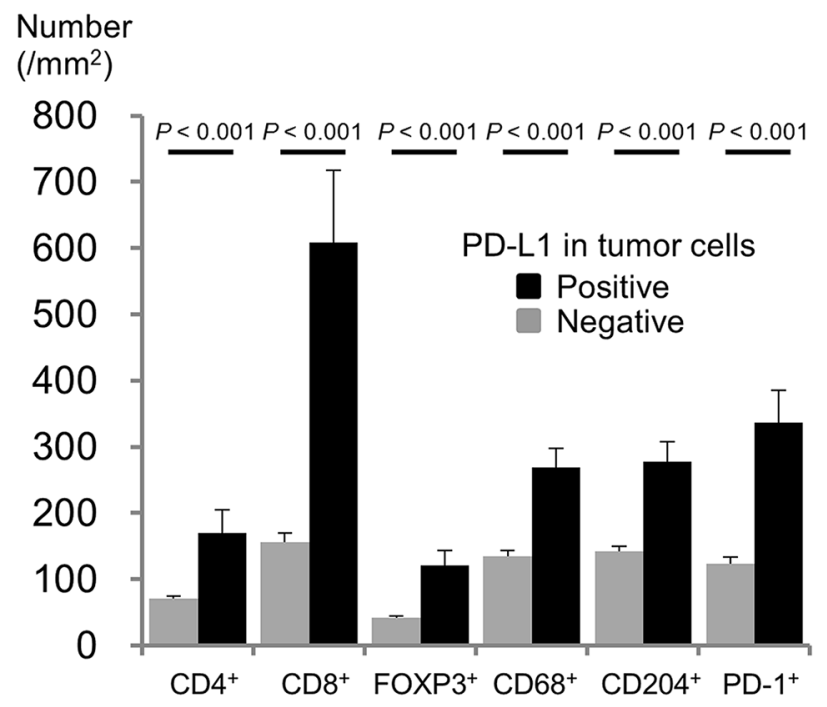

C

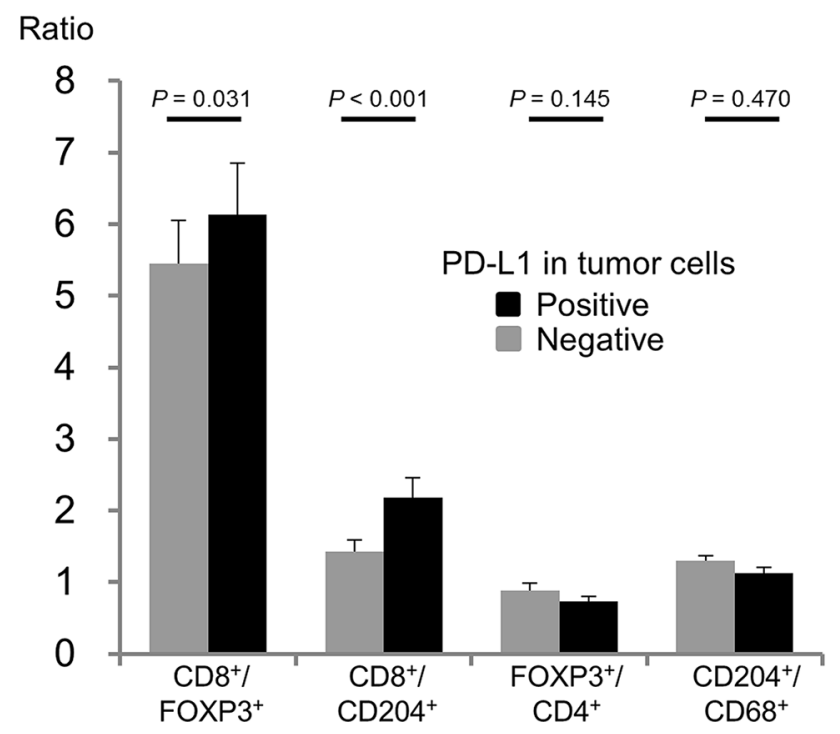

a significant association with OS except for $\mathrm{PD}-1^{+}$ cells (HR $0.579,95 \%$ CI: $0.387-0.865, P=0.008$ ). We explored OS based on TIICs in the stroma by focusing on factors significantly impacting OS in the tumor nest assessment $\left(\mathrm{CD} 8^{+} / \mathrm{FOXP}^{+}, \mathrm{CD}^{+} / \mathrm{CD} 204^{+}\right.$, and $\left.\mathrm{PD}-1^{+}\right)$. None significantly impacted OS in multivariate analyses (Supplementary Figure S3).

\section{DISCUSSION}

We clarified PD-1 and PD-L1 expressions, the associations between PD-L1 expression and various immune cells, and the prognostic relevance of these factors

B

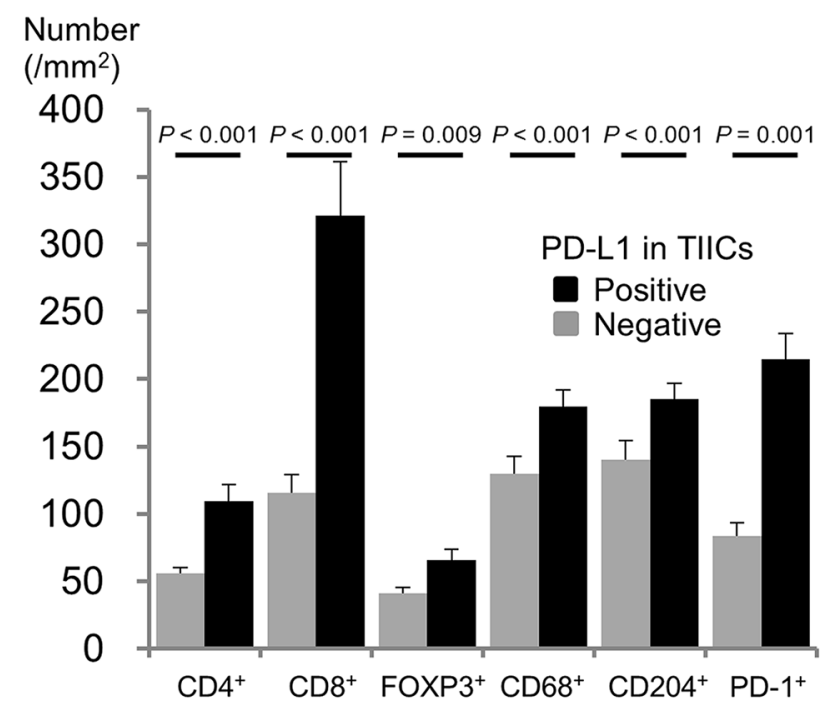

D

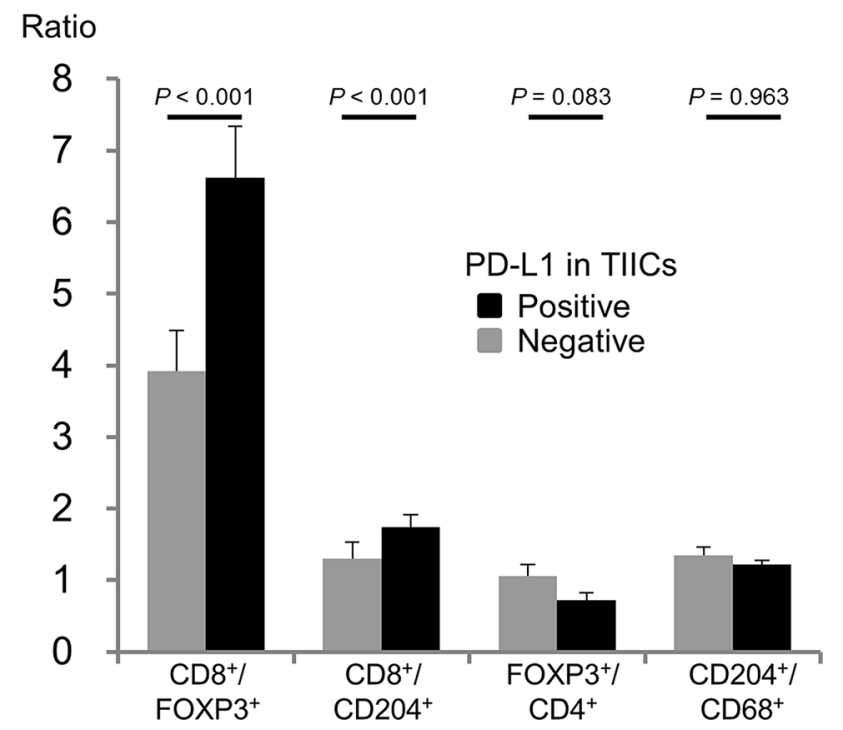

Figure 2: Associations between PD-L1 expression and tumor infiltrating immune cells. (A) Density of each immune cell type according to PD-L1 expression in TCs. (B) Density of each immune cell type according to PD-L1 expression in TIICs. (C) Immune cell ratios according to PD-L1 expression in TCs. (D) Immune cell ratios according to PD-L1 expression in TIICs. 
Table 2: PD-L1 expressions in tumor cells and tumor infiltrating immune cells

\begin{tabular}{|c|c|c|c|c|}
\hline \multicolumn{2}{|c}{ Total } & Positive & \% & 95\% CI \\
\hline TCs & 196 & 36 & 18.4 & $13.2-24.5$ \\
\hline TIICs & 196 & 119 & 60.7 & $53.5-67.6$ \\
\hline
\end{tabular}

\begin{tabular}{|c|c|c|c|c|}
\hline & & \multicolumn{2}{|c|}{ TIICs } & \multirow{2}{*}{$\begin{array}{c}P \text { value } \\
\text { (McNemar) }\end{array}$} \\
\hline & & Negative & Positive & \\
\hline \multirow{2}{*}{ TCs } & Negative & $71(44.4 \%)$ & $89(55.6 \%)$ & \multirow{2}{*}{$<0.001$} \\
\hline & Positive & $6(16.7 \%)$ & $30(83.3 \%)$ & \\
\hline
\end{tabular}

Abbreviations: TCs, tumor cells; TIICs, tumor infiltrating immune cells.

A

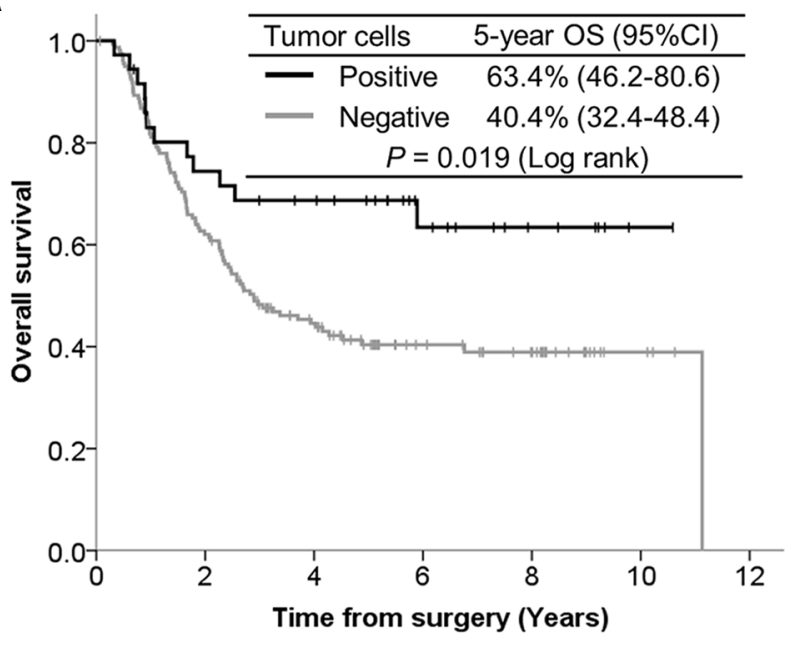

B

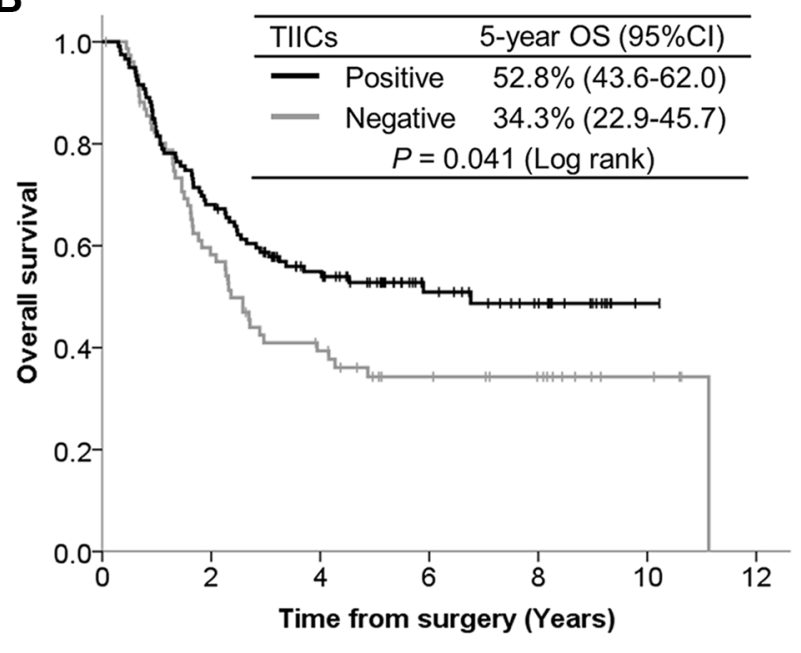

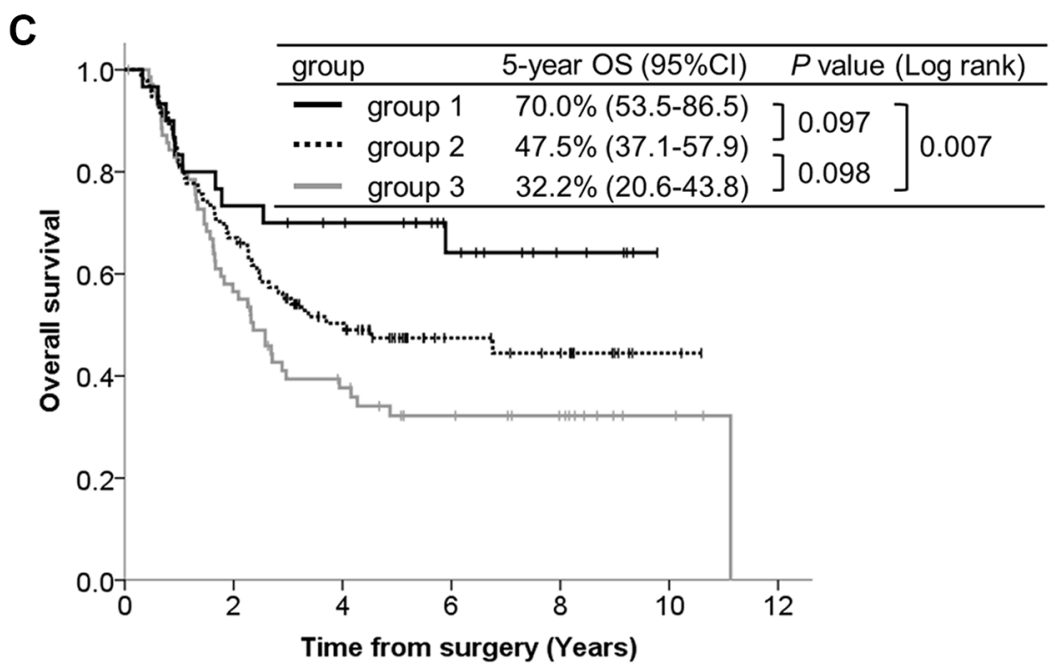

Figure 3: Kaplan-Meier curves according to PD-L1 expression, with 5-year survival rate and the log-rank test for OS. (A) PD-L1 expression in TCs. (B) PD-L1 expression in TIICs. (C) Utility of combining PD-L1 expressions in TCs and TIICs; group 1 $(n=30)$ : Both TCs and TIICs are PD-L1 positive, group $2(n=95)$ : either TCs or TIICs are PD-L1 positive, group 3 ( $n=71)$ : both TCs and TIICs are PD-L1 negative. 
Table 3: Univariate and multivariate Cox regression analyses for overall survival

\begin{tabular}{|c|c|c|c|c|c|}
\hline \multicolumn{3}{|l|}{ Univariate analysis } & \multicolumn{3}{|c|}{ Overall survival } \\
\hline Clinicopathological factors & & ref & HR & $95 \% \mathrm{CI}$ & $P$ \\
\hline Age & $>65$ & $\leq 65$ & 0.866 & $0.588-1.274$ & 0.465 \\
\hline Gender & Female & Male & 0.771 & $0.452-1.314$ & 0.339 \\
\hline Smoking status & Smoker & Non-smoker & 1.355 & $0.815-2.252$ & 0.242 \\
\hline Alcohol consumption & Drinker & Non-drinker & 0.969 & $0.541-1.733$ & 0.914 \\
\hline Location & lower & Upper/Middle & 0.893 & $0.606-1.315$ & 0.566 \\
\hline pT factor & 4 & $2-3$ & 1.600 & $0.587-4.361$ & 0.358 \\
\hline LN metastasis & Present & Absent & 3.274 & $1.827-5.867$ & $<0.001$ \\
\hline Histological grade & $\mathrm{P} / \mathrm{D}$ & $\mathrm{W} / \mathrm{D}, \mathrm{M} / \mathrm{D}$ & 1.857 & $1.073-3.213$ & 0.027 \\
\hline Lymphatic invasion & Present & Absent & 2.180 & $1.454-3.269$ & $<0.001$ \\
\hline Venous invasion & Present & Absent & 1.628 & $0.848-3.125$ & 0.143 \\
\hline \multicolumn{2}{|l|}{ Immunological factors } & ref & HR & $95 \% \mathrm{CI}$ & $P$ \\
\hline PD-L1 (TCs) & Positive & Negative & 0.493 & $0.270-0.901$ & 0.022 \\
\hline PD-L1 (TIICs) & Positive & Negative & 0.670 & $0.455-0.986$ & 0.042 \\
\hline CD4 & High & Low & 0.786 & $0.535-1.154$ & 0.219 \\
\hline CD8 & High & Low & 0.668 & $0.454-0.984$ & 0.041 \\
\hline FOXP3 & High & Low & 1.279 & $0.868-1.885$ & 0.213 \\
\hline PD-1 & High & Low & 0.656 & $0.445-0.967$ & 0.033 \\
\hline CD68 & High & Low & 0.877 & $0.597-1.289$ & 0.505 \\
\hline CD204 & High & Low & 1.239 & $0.842-1.824$ & 0.276 \\
\hline $\mathrm{CD}^{+} / \mathrm{FOXP}^{+}$ & High & Low & 0.601 & $0.406-0.890$ & 0.011 \\
\hline $\mathrm{CD}^{+} / \mathrm{CD} 204^{+}$ & High & Low & 0.641 & $0.435-0.946$ & 0.025 \\
\hline $\mathrm{FOXP}^{+} / \mathrm{CD}^{+}$ & High & Low & 1.509 & $1.023-2.225$ & 0.038 \\
\hline $\mathrm{CD} 204^{+} / \mathrm{CD} 68^{+}$ & High & Low & 1.219 & $0.828-1.795$ & 0.315 \\
\hline \multicolumn{3}{|l|}{ Multivariate analysis ${ }^{\#}$} & \multicolumn{3}{|c|}{ Overall survival } \\
\hline Immunological factors & & ref & HR & $95 \% \mathrm{CI}$ & $\boldsymbol{P}$ \\
\hline PD-L1 (TCs) & Positive & Negative & 0.461 & $0.246-0.864$ & 0.016 \\
\hline PD-L1 (TIICs) & Positive & Negative & 0.590 & $0.394-0.884$ & 0.010 \\
\hline CD4 & High & Low & 0.787 & $0.527-1.175$ & 0.599 \\
\hline CD8 & High & Low & 0.693 & $0.456-1.052$ & 0.085 \\
\hline FOXP3 & High & Low & 1.267 & $0.837-1.918$ & 0.263 \\
\hline PD-1 & High & Low & 0.579 & $0.387-0.865$ & 0.008 \\
\hline CD68 & High & Low & 1.009 & $0.668-1.526$ & 0.964 \\
\hline CD204 & High & Low & 1.299 & $0.866-1.964$ & 0.206 \\
\hline $\mathrm{CD}^{+} / \mathrm{FOXP}^{+}$ & High & Low & 0.617 & $0.413-0.923$ & 0.019 \\
\hline $\mathrm{CD}^{+} / \mathrm{CD} 204^{+}$ & High & Low & 0.650 & $0.439-0.962$ & 0.031 \\
\hline $\mathrm{FOXP}^{+} / \mathrm{CD}^{+}$ & High & Low & 1.381 & $0.922-2.067$ & 0.117 \\
\hline $\mathrm{CD} 204^{+} / \mathrm{CD} 68^{+}$ & High & Low & 1.106 & $0.742-1.648$ & 0.621 \\
\hline
\end{tabular}

Abbreviations: HR, hazard ratio; CI, confidence interval; LN, lymph node; W/D, well differentiated; M/D, moderately differentiated; P/D, poorly differentiated; TCs, tumor cells; TIICs, tumor infiltrating immune cells.

\#adjusted for age, gender, smoking habit, alcohol consumption, pT factor, LN metastasis, histological grade, lymphatic invasion, and venous invasion. 
employing IHC with tissue microarrays for 196 ESCC cases who had received neither preoperative neoadjuvant therapy nor post-recurrence immunotherapy.

Reports of PD-L1 expression in ESCC are limited. PD-L1 positive rates in TCs were reported to be $41.9 \%$ by Ohigashi et al. and $84.5 \%$ by Chen et al. [21, 22], though PD-L1 expressions on the plasma membrane and in the cytoplasm were defined as positive in their studies. Mechanistically, PD-L1 is a type I transmembrane molecule expressed on TCs and binds to its receptor, PD-1, which is expressed on the plasma membranes of activated T cells [27]. Furthermore, PD-L1 expression on the plasma membrane has been evaluated as a biomarker candidate in recent clinical trials of anti-PD-1 or anti-PD-L1 antibody therapy [17-19]. Accordingly, we evaluated PD-L1 expression on the plasma membranes of TCs employing a cut-off value of $1 \%$ based on the sensitivity test assessing hazard ratios for OS, and demonstrated the positive rate to be $18.4 \%$ in our patients. The positive rate of $63.8 \%$ for PD-L1 expression in TCs and/or TIICs demonstrated herein was compatible with the results of a phase 1 trial for esophageal cancer [15].

A

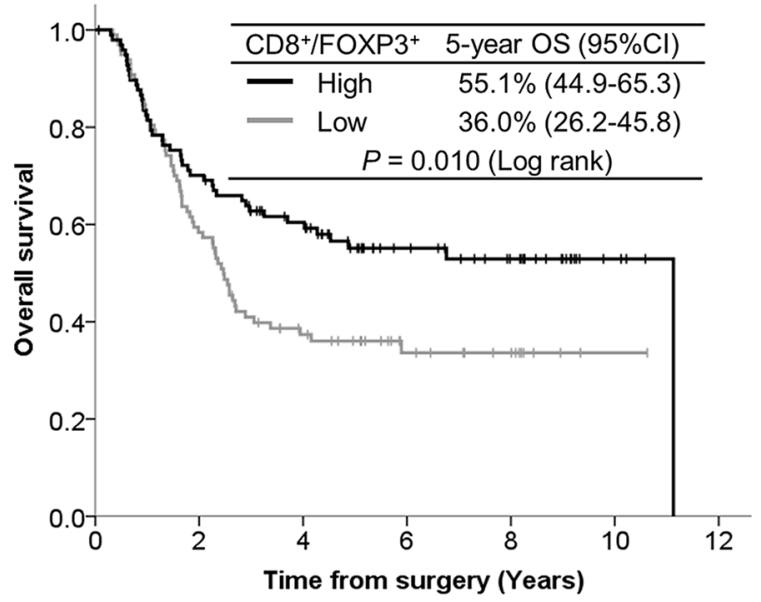

C

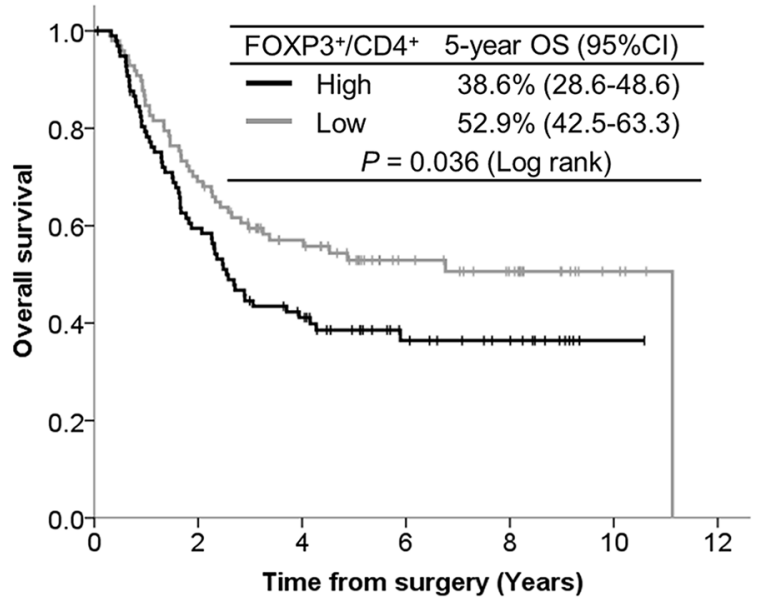

Marked infiltration of $\mathrm{CD}^{+}$cells into a $\mathrm{PD}-\mathrm{L} 1$ positive tumor has been reported for several cancers including ESCC $[21,28,29]$. In this study, abundant infiltrations of $\mathrm{CD}^{+}$ and $\mathrm{PD}-1^{+}$cells were associated with PD-L1 expression in TCs and TIICs, observations in line with the theory that PD-L1 expression is induced by several pro-inflammatory factors, such as IFN $\gamma$ and TNF $\alpha$, produced by activated $\mathrm{T}$ cells $[30,31]$, and that the PD-1/PD-L1 pathway plays a role in suppressing activated $\mathrm{T}$ cells in the periphery. In addition, marked infiltrations of immune suppressor cells such as regulatory $\mathrm{T}$ cells $\left(\mathrm{FOXP} 3^{+}\right)$and $\mathrm{M} 2$ macrophages $\left(\mathrm{CD} 204^{+}\right)$were also associated with PD-L1 expression in both TCs and TIICs. These results indicate that PD-L1 expression in TCs and/or TIICs reflects a highly activated immune response to tumors and also the adaptive immune resistance which develops as a consequence. In contrast, significant associations of positivity for PD-L1 expression with the $\mathrm{CD}^{+} / \mathrm{FOXP}^{+}$and $\mathrm{CD}^{+} / \mathrm{CD} 204^{+}$ratios, as well as a trend for an inverse association of PD-L1 expression with the $\mathrm{FOXP}^{+} / \mathrm{CD}^{+}$ratio, were observed, suggesting PD-L1 expression to be associated with the balance between infiltrating effector cells and immune suppressor cells.

B

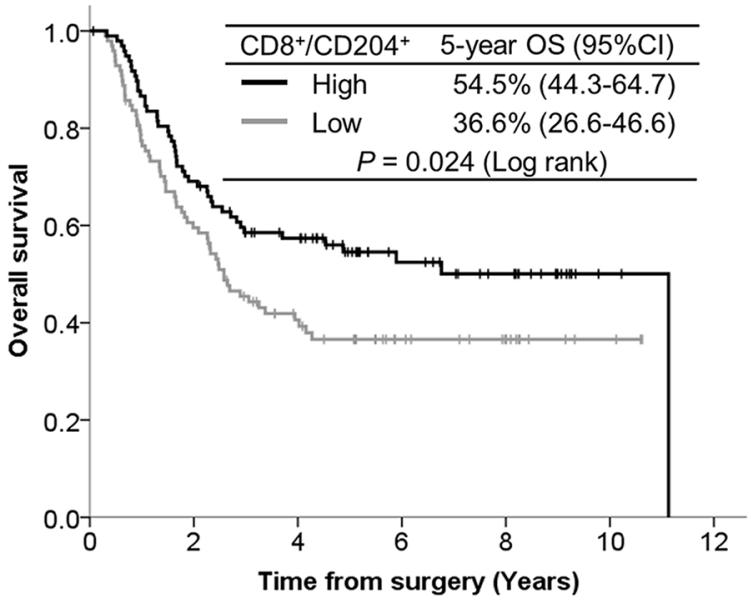

$\mathbf{D}$

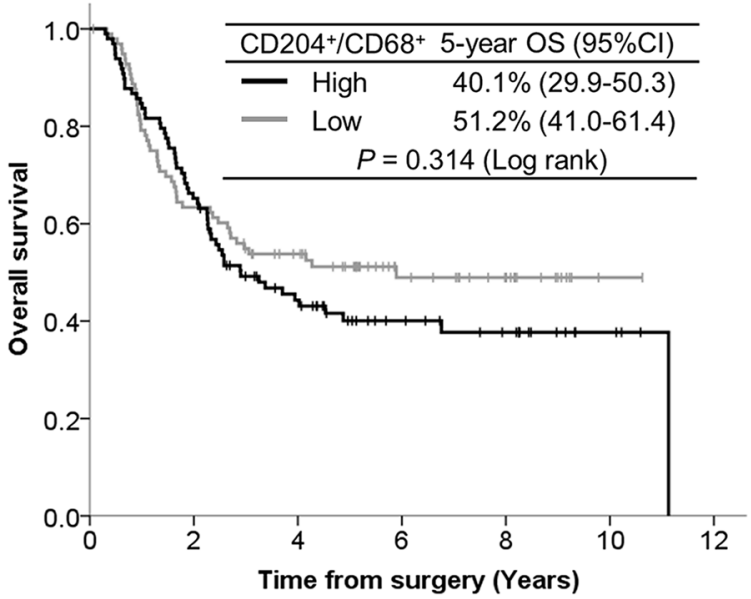

Figure 4: Kaplan-Meier curves according to TIIC ratios, with 5-year survival rate and the log-rank test for OS. (A) $\mathrm{CD}^{+} / \mathrm{FOXP}^{+}$ratio. (B) $\mathrm{CD}^{+} / \mathrm{CD} 204^{+}$ratio. (C) $\mathrm{FOXP}^{+} / \mathrm{CD}^{+}$ratio. (D) $\mathrm{CD} 204^{+} / \mathrm{CD} 68^{+}$ratio. 
The prognostic significance of PD-L1 expression in TCs remains controversial. Previous studies of ESCC demonstrated an association between PD-L1 expression and poor outcomes [21, 22]. However, we found PD-L1 expression to be a factor predicting favorable OS. Similar discordant results have also been reported for other cancers, such as melanoma and lung cancer [32-36]. We speculate that this discrepancy regarding prognostic relevance between the present and previous studies may be due not only to the definitions of positive staining applied, but also differences in the antibodies used and heterogeneous baseline characteristics. We also revealed PD-L1 expression in TIICs and high infiltration of PD- $1^{+}$ TIICs to predict favorable OS, which is compatible with recent reports on several cancer types [29, 37-40]. PD-1 and PD-L1 are inhibitory immune checkpoint molecules. However, considering that PD-1 is expressed mainly on activated $\mathrm{T}$ cells and PD-L1 expression is induced by activated $\mathrm{T}$ cells, and also the association between PD- L1 expression and TIIC abundance including PD- $1^{+}$ cells, PD-1 and PD-L1 expressions should be regarded as reflecting an immunoreactive state, which contributes to better OS [9]. PD-L1 positive tumors, which generally have abundant TIICs including PD- $1^{+}$immune cells, may define a subset of ESCC patients who are potential candidates for anti-PD-1 or anti-PD-L1 antibody therapy. However, we cannot draw a conclusion based on our present results as this study did not include patients receiving these agents. Ongoing clinical trials of these agents are anticipated to clarify the optimal predictive biomarkers.

The number of tumor infiltrating $\mathrm{FOXP}^{+}$regulatory $\mathrm{T}$ cells, especially as reflected by a decreased $\mathrm{CD}^{+} /$ $\mathrm{FOXP}^{+}$ratio, is reportedly associated with a poor prognosis for several cancer types [41-44]. In addition to confirming these prior reports, our results clarified the prognostic significance of the $\mathrm{CD}^{+} / \mathrm{CD} 204^{+}$ratio. CD204 macrophages are another set of immune suppressor cells (M2 phenotype) [45], and marked CD204 macrophage infiltration is reportedly associated with a malignant phenotype or poor survival for several cancers including ESCC [26, 46-48]. Given the functions of M2 macrophages, such as producing immune suppressive cytokines and downregulating effector $\mathrm{T}$ cell activity $[49,50]$, not only the number of CD204+ cells but also the balance between $\mathrm{CD}^{+}$and $\mathrm{CD} 204^{+}$cells must be considered. Our study is the first, to our knowledge, to demonstrate the positive survival impact of an increased $\mathrm{CD}^{+} / \mathrm{CD} 204^{+}$ratio. These results suggest that regulatory $\mathrm{T}$ cells and M2 macrophages play a critical role in ESCC progression, making these cell types potentially novel therapeutic targets for agents which could be used in addition to immune checkpoint inhibitors targeting PD-1/ PD-L1 signaling.

Herein, TIICs in the stroma were not associated with OS. The clinical relevance of TIIC localization, whether in the tumor nest or the stroma, remains controversial. Although several reports have demonstrated the importance of the stroma [51-53], our results indicate that tumor nest TIICs have more clinical relevance in ESCC. Tumor microenvironments may differ among cancer types. The present results are understandable, considering that tumor nest TIICs are in direct contact with TCs. A report on melanoma showed lymphocytes within the tumor nests to be remarkably increased after immune checkpoint inhibitor treatment in patients who demonstrated a response, suggesting the importance of tumor nest TIICs [54].

We examined for the first time the impacts of various immunological factors in both TCs and TIICs from a large cohort of patients with pure ESCC. Although we enrolled 196 patients, a considerable number, this study was performed retrospectively, in a single institution. A prospective study is needed to validate the present results.

In summary, we employed comprehensive IHC analyses in patients with ESCC. We demonstrated PD- L1 expression in a significant proportion of patients with ESCC, its association with marked infiltration of TIICs, the prognostic significance of PD-1 and PD-L1 expressions and the impact on clinical outcomes of the balance between infiltrating effector cells and immune suppressor cells. Given the complex network constituting anti-tumor immunity, such comprehensive analyses should be applied when assessing immune status in the tumor microenvironment.

\section{MATERIALS AND METHODS}

\section{Patients and specimens}

Among the 372 patients with no prior therapy who underwent surgical resection of esophageal cancer between 2000 and 2011 at the National Cancer Center Hospital East, Kashiwa, Japan, 196 were consecutively enrolled in this study based on the following selection criteria: i) histologically confirmed squamous cell carcinoma, ii) pathological $\mathrm{T}$ factor of at least $\mathrm{T} 2$ according to the TNM classification [55], iii) complete resection performed, iv) no in-hospital death after surgery, and v) sufficient formalin-fixed paraffin-embedded surgically resected tissue sample amounts available. Clinical and pathological information was collected from medical records including the pathology report for each subject. The study protocol was approved by the institutional review board of the National Cancer Center in October 2014 (2014-124). The study was carried out according to the Epidemiological Study Guideline of the Ministry of Health, Labour and Welfare of Japan. We disclosed the study design on the National Cancer Center website and gave the relatives of deceased patients the opportunity to decline participation.

After reviewing hematoxylin and eosin (H\&E) slides of the archived primary tumors, a representative block was selected in each case. A 2.0-mm in diameter 
tumor core was obtained from the center of the selected block, using a manual tissue arrayer (Azumaya Ika Kikai, Tokyo, Japan). These cores were assembled in a tissue microarray (TMA) format, and paraffin-embedded TMA blocks were then cut into 4-mm sections and placed on silicon-coated slides for IHC staining.

\section{Immunohistochemistry}

The primary antibodies used for IHC and the IHC assay are described in Supplementary Table S1. For CD4, CD8 and CD68, IHC was performed employing ready-to-use antibodies and the fully automated Ventana Benchmark ULTRA platform (Ventana, Tucson, AZ, USA) according to the manufacturer's instructions. For CD204, IHC was performed using the Ventana Benchmark ULTRA platform semi-automatically with manual application of the primary antibody. For FOXP3, PD-1 and PD-L1, IHC was performed manually.

\section{Evaluation of PD-L1 expression and tumor infiltrating immune cells}

After IHC, the slides were scanned and the microscopic images were imported as digital photo files using the NanoZoomer Digital Pathology (NDP) system (Hamamatsu Photonics, Hamamatsu, Japan). PD-L1 expression was identified by two independent observers (KH and SF) blinded to all of the clinical data. To assess PD-L1 in TCs, the proportion of TCs with membrane staining was scored as $<1 \%, 1-4 \%, 5-9 \%, 10 \%$, and then at $10 \%$ intervals up to $\geq 50 \%$. When the difference between the assessments of the two pathologists was one level or greater, the slide was reviewed jointly and a single consensus score was established. Finally, PD-L1 positive expression in TCs was defined as the presence of $\geq 1 \%$ of TCs with membrane staining based on the hazard ratio for OS (Supplementary Figure S1). PD-L1 expression in TIICs was determined qualitatively to be either positive (any expression of PD-L1 in TIICs in the core) or negative (no staining).

To quantitatively evaluate each TIIC type, the entire tumor core was reviewed using NDP view at a magnification of $\times 200$ and 4 independent areas with a size of $0.0625 \mathrm{~mm}^{2}$, containing the greatest abundance of TIICs in the tumor nest, were selected. After counting the TIICs in each selected area using NDP view at a magnification of $\times 400$, numbers of the respective TIICs per square millimeter calculated from the total number in the 4 selected areas were presented. We calculated ratios of infiltrating effector cells to immune suppressor cells, such as $\mathrm{CD}^{+} / \mathrm{FOXP}^{+}\left(\mathrm{CD}^{+}\right.$cell count divided by $\mathrm{FOXP3}^{+}$ cell count) and $\mathrm{CD}^{+} / \mathrm{CD} 204^{+}$, and ratios of the infiltrating immune suppressor cells to the corresponding whole cell populations, such as $\mathrm{FOXP} 3^{+} / \mathrm{CD}^{+}$and $\mathrm{CD} 204^{+} / \mathrm{CD} 68^{+}$, were also determined.

\section{Statistical analysis}

The numbers of each TIIC type were compared according to PD-L1 expression status (positive/negative), in TCs and TIICs, using the Mann-Whitney $U$ test. The Chi-square test was applied to assess the relationships between clinicopathological factors and PD-L1 expressions in TCs and TIICs, and the McNemar test was used to compare the proportions positive for PD-L1 expression between TCs and TIICs. OS was defined as the period from the date of surgery until the date of death from any cause. Patients were censored at the time of their last follow-up, if they were alive. OS rates were estimated using the Kaplan-Meier method, and were compared using the log-rank test. Immunological factors other than PDL1 expression status were dichotomized according to their median values $(\geq$ median $/<$ median $)$.

Univariate and multivariate Cox proportional hazards models were used to examine the associations of clinicopathological factors with OS. The impacts of immunological factors (PD-L1 expressions in TCs and TIICs, number of each type of TIIC, and TIIC ratios $\left[\mathrm{CD}^{+} / \mathrm{FOXP}^{+}, \mathrm{CD}^{+} / \mathrm{CD}^{2} 04^{+}, \mathrm{FOXP}^{+} / \mathrm{CD}^{+}\right.$ and $\left.\mathrm{CD} 204^{+} / \mathrm{CD} 68^{+}\right]$) on $\mathrm{OS}$ were first examined with univariate Cox regression models. Next, the impact of each immunological factor on OS was assessed by adding each factor to the multivariate model which contained the possibly confounding clinicopathological factors such as age, gender, smoking status, alcohol consumption, location, pT factor, lymph node metastasis, histological grade, lymphatic invasion, and venous invasion. All statistical analyses were performed using IBM SPSS statistics 20 (IBM Japan Ltd., Tokyo, Japan). All $P$ values were two-sided, with a significance level of 0.05 .

\section{ACKNOWLEDGMENTS}

We are grateful to Ms. Yuka Nakamura and Ms. Mari Takahashi for a technical assistance.

\section{CONFLICTS OF INTEREST}

The authors have no potential conflicts of interest related to this work.

\section{GRANT SUPPORT}

This study was supported by research funding from the National Cancer Center Hospital East and a Health and Labor Science Research Grant.

\section{REFERENCES}

1. Pennathur A, Gibson MK, Jobe BA, Luketich JD. Oesophageal carcinoma. Lancet. 2013; 381:400-412. 
2. Enzinger PC, Mayer RJ. Esophageal cancer. N Engl J Med. 2003; 349:2241-2252.

3. Shimazu T, Inoue M, Sasazuki S, Iwasaki M, Kurahashi N, Yamaji T, Tsugane S, Japan Public Health Center-based Prospective Study G. Alcohol and risk of lung cancer among Japanese men: data from a large-scale populationbased cohort study, the JPHC study. Cancer Causes Control. 2008; 19:1095-1102.

4. Bagnardi V, Rota M, Botteri E, Tramacere I, Islami F, Fedirko V, Scotti L, Jenab M, Turati F, Pasquali E, Pelucchi C, Galeone C, Bellocco R, et al. Alcohol consumption and sitespecific cancer risk: a comprehensive dose-response metaanalysis. Br J Cancer. 2015; 112:580-593.

5. Hecht SS. Tobacco carcinogens, their biomarkers and tobacco-induced cancer. Nat Rev Cancer. 2003; 3:733-744.

6. Liu Y, Chen H, Sun Z, Chen X. Molecular mechanisms of ethanol-associated oro-esophageal squamous cell carcinoma. Cancer Lett. 2015; 361:164-173.

7. Lin DC, Hao JJ, Nagata Y, Xu L, Shang L, Meng X, Sato Y, Okuno Y, Varela AM, Ding LW, Garg M, Liu LZ, Yang H, et al. Genomic and molecular characterization of esophageal squamous cell carcinoma. Nat Genet. 2014; 46:467-473.

8. Vogelstein B, Papadopoulos N, Velculescu VE, Zhou S, Diaz LA, Jr., Kinzler KW. Cancer genome landscapes. Science. 2013; 339:1546-1558.

9. Topalian SL, Drake CG, Pardoll DM. Targeting the PD-1/ B7-H1(PD-L1) pathway to activate anti-tumor immunity. Curr Opin Immunol. 2012; 24:207-212.

10. Spira AI, Park K, Mazieres J, Vansteenkiste JF, Rittmeyer A, Ballinger M, Waterkamp D, Kowanetz M, Mokatrin A, Fehrenbacher L. Efficacy, safety and predictive biomarker results from a randomized phase II study comparing MPDL3280A vs docetaxel in 2L/3L NSCLC (POPLAR). ASCO Annual Meeting. Chicago, 2015:Abstract 8010.

11. Gettinger SN, Horn L, Gandhi L, Spigel DR, Antonia SJ, Rizvi NA, Powderly JD, Heist RS, Carvajal RD, Jackman DM, Sequist LV, Smith DC, Leming P, et al. Overall Survival and Long-Term Safety of Nivolumab (Anti-Programmed Death 1 Antibody, BMS-936558, ONO4538) in Patients With Previously Treated Advanced NonSmall-Cell Lung Cancer. J Clin Oncol. 2015; 33:2004-2012.

12. McDermott DF, Drake CG, Sznol M, Choueiri TK, Powderly JD, Smith DC, Brahmer JR, Carvajal RD, Hammers HJ, Puzanov I, Hodi FS, Kluger HM, Topalian SL, et al. Survival, Durable Response, and LongTerm Safety in Patients With Previously Treated Advanced Renal Cell Carcinoma Receiving Nivolumab. J Clin Oncol. 2015; 33:2013-2020.

13. Song Y, Li L, Ou Y, Gao Z, Li E, Li X, Zhang W, Wang J, Xu L, Zhou Y, Ma X, Liu L, Zhao Z, et al. Identification of genomic alterations in oesophageal squamous cell cancer. Nature. 2014; 509:91-95.

14. Brahmer J, Reckamp KL, Baas P, Crino L, Eberhardt WE, Poddubskaya E, Antonia S, Pluzanski A, Vokes EE, Holgado E, Waterhouse D, Ready N, Gainor J, et al. Nivolumab versus
Docetaxel in Advanced Squamous-Cell Non-Small-Cell Lung Cancer. N Engl J Med. 2015; 373:123-135.

15. Doi T, Piha-Paul SA, Jalal SI, Mai-Dang H, Yuan S, Koshiji M, Csiki I, Bennouna J. Pembrolizumab (MK-3475) for patients (pts) with advanced esophageal carcinoma: Preliminary results from KEYNOTE-028. ASCO Annual Meeting. Chicago, 2015:Abstract 4010.

16. Ura $\mathrm{T}$, Muro K, Hara $\mathrm{H}$, Yamaguchi $\mathrm{K}$, Hironaka $\mathrm{S}$, Iwasa S, Kato K, Kojima T, Tsushima T, Yasui H, Satoh T, Doki Y, Ohtsu A, et al. Phase 2 study of Nivolumab (AntiPD-1; ONO-4538) in Patients with Esophageal Cancer: Preliminary Report. The European Cancer Congress. Vienna, 2015:Abstract 2301.

17. Taube JM, Klein A, Brahmer JR, Xu H, Pan X, Kim JH, Chen L, Pardoll DM, Topalian SL, Anders RA. Association of PD-1, PD-1 ligands, and other features of the tumor immune microenvironment with response to anti-PD-1 therapy. Clin Cancer Res. 2014; 20:5064-5074.

18. Garon EB, Rizvi NA, Hui R, Leighl N, Balmanoukian AS, Eder JP, Patnaik A, Aggarwal C, Gubens M, Horn L, Carcereny E, Ahn MJ, Felip E, et al. Pembrolizumab for the treatment of non-small-cell lung cancer. N Engl J Med. 2015; 372:2018-2028.

19. Herbst RS, Soria JC, Kowanetz M, Fine GD, Hamid O, Gordon MS, Sosman JA, McDermott DF, Powderly JD, Gettinger SN, Kohrt HE, Horn L, Lawrence DP, et al. Predictive correlates of response to the anti-PD-L1 antibody MPDL3280A in cancer patients. Nature. 2014; 515:563-567.

20. Le DT, Uram JN, Wang H, Bartlett BR, Kemberling H, Eyring AD, Skora AD, Luber BS, Azad NS, Laheru D, Biedrzycki B, Donehower RC, Zaheer A, et al. PD-1 Blockade in Tumors with Mismatch-Repair Deficiency. N Engl J Med. 2015; 372:2509-2520.

21. Ohigashi Y, Sho M, Yamada Y, Tsurui Y, Hamada K, Ikeda N, Mizuno T, Yoriki R, Kashizuka H, Yane K, Tsushima F, Otsuki N, Yagita H, et al. Clinical significance of programmed death-1 ligand-1 and programmed death-1 ligand-2 expression in human esophageal cancer. Clin Cancer Res. 2005; 11:2947-2953.

22. Chen L, Deng H, Lu M, Xu B, Wang Q, Jiang J, Wu C. B7-H1 expression associates with tumor invasion and predicts patient's survival in human esophageal cancer. Int J Clin Exp Pathol. 2014; 7:6015-6023.

23. Rizvi NA, Hellmann MD, Snyder A, Kvistborg P, Makarov V, Havel JJ, Lee W, Yuan J, Wong P, Ho TS, Miller ML, Rekhtman N, Moreira AL, et al. Cancer immunology. Mutational landscape determines sensitivity to PD-1 blockade in non-small cell lung cancer. Science. 2015; 348:124-128.

24. Cho Y, Miyamoto M, Kato K, Fukunaga A, Shichinohe T, Kawarada Y, Hida Y, Oshikiri T, Kurokawa T, Suzuoki M, Nakakubo Y, Hiraoka K, Murakami S, et al. CD4+ and CD8+ T cells cooperate to improve prognosis of patients with esophageal squamous cell carcinoma. Cancer Res. 2003; 63:1555-1559. 
25. Yoshioka T, Miyamoto $\mathrm{M}$, Cho $\mathrm{Y}$, Ishikawa $\mathrm{K}$, Tsuchikawa T, Kadoya M, Li L, Mishra R, Ichinokawa K, Shoji Y, Matsumura Y, Shichinohe T, Hirano S, et al. Infiltrating regulatory $\mathrm{T}$ cell numbers is not a factor to predict patient's survival in oesophageal squamous cell carcinoma. Br J Cancer. 2008; 98:1258-1263.

26. Shigeoka M, Urakawa $N$, Nakamura $T$, Nishio $M$, Watajima T, Kuroda D, Komori T, Kakeji Y, Semba S, Yokozaki H. Tumor associated macrophage expressing CD204 is associated with tumor aggressiveness of esophageal squamous cell carcinoma. Cancer Sci. 2013; 104:1112-1119.

27. Dong H, Zhu G, Tamada K, Chen L. B7-H1, a third member of the B7 family, co-stimulates T-cell proliferation and interleukin-10 secretion. Nat Med. 1999; 5:1365-1369.

28. Lipson EJ, Vincent JG, Loyo M, Kagohara LT, Luber BS, Wang $\mathrm{H}, \mathrm{Xu} \mathrm{H}$, Nayar SK, Wang TS, Sidransky D, Anders RA, Topalian SL, Taube JM. PD-L1 expression in the Merkel cell carcinoma microenvironment: association with inflammation, Merkel cell polyomavirus and overall survival. Cancer Immunol Res. 2013; 1:54-63.

29. Kim MY, Koh J, Kim S, Go H, Jeon YK, Chung DH. Clinicopathological analysis of PD-L1 and PD-L2 expression in pulmonary squamous cell carcinoma: Comparison with tumor-infiltrating T cells and the status of oncogenic drivers. Lung Cancer. 2015; 88:24-33.

30. Ostrand-Rosenberg S, Horn LA, Haile ST. The programmed death-1 immune-suppressive pathway: barrier to antitumor immunity. J Immunol. 2014; 193:3835-3841.

31. Kondo A, Yamashita T, Tamura H, Zhao W, Tsuji T, Shimizu M, Shinya E, Takahashi H, Tamada K, Chen L, Dan K, Ogata K. Interferon-gamma and tumor necrosis factor-alpha induce an immunoinhibitory molecule, B7-H1, via nuclear factor-kappaB activation in blasts in myelodysplastic syndromes. Blood. 2010; 116:1124-1131.

32. Yang CY, Lin MW, Chang YL, Wu CT, Yang PC. Programmed cell death-ligand 1 expression in surgically resected stage I pulmonary adenocarcinoma and its correlation with driver mutations and clinical outcomes. Eur J Cancer. 2014; 50:1361-1369.

33. Zhang Y, Wang L, Li Y, Pan Y, Wang R, Hu H, Li H, Luo X, Ye T, Sun Y, Chen H. Protein expression of programmed death 1 ligand 1 and ligand 2 independently predict poor prognosis in surgically resected lung adenocarcinoma. Onco Targets Ther. 2014; 7:567-573.

34. Gadiot J, Hooijkaas AI, Kaiser AD, van Tinteren H, van Boven H, Blank C. Overall survival and PD-L1 expression in metastasized malignant melanoma. Cancer. 2011; 117:2192-2201.

35. Hino R, Kabashima K, Kato Y, Yagi H, Nakamura M, Honjo T, Okazaki T, Tokura Y. Tumor cell expression of programmed cell death-1 ligand 1 is a prognostic factor for malignant melanoma. Cancer. 2010; 116:1757-1766.

36. Taube JM, Anders RA, Young GD, Xu H, Sharma R, McMiller TL, Chen S, Klein AP, Pardoll DM, Topalian SL,
Chen L. Colocalization of inflammatory response with B7-h1 expression in human melanocytic lesions supports an adaptive resistance mechanism of immune escape. Sci Transl Med. 2012; 4:127ra137.

37. Bellmunt J, Mullane SA, Werner L, Fay AP, Callea M, Leow JJ, Taplin ME, Choueiri TK, Hodi FS, Freeman GJ, Signoretti S. Association of PD-L1 expression on tumorinfiltrating mononuclear cells and overall survival in patients with urothelial carcinoma. Ann Oncol. 2015.

38. Choueiri TK, Fay AP, Gray KP, Callea M, Ho TH, Albiges L, Bellmunt J, Song J, Carvo I, Lampron M, Stanton ML, Hodi FS, McDermott DF, et al. PD-L1 expression in nonclear-cell renal cell carcinoma. Ann Oncol. 2014; 25:2178-2184.

39. Darb-Esfahani S, Kunze CA, Kulbe H, Sehouli J, Wienert S, Lindner J, Budczies J, Bockmayr M, Dietel M, Denkert C, Braicu I, Johrens K. Prognostic impact of programmed cell death-1 (PD-1) and PD-ligand 1 (PD-L1) expression in cancer cells and tumor-infiltrating lymphocytes in ovarian high grade serous carcinoma. Oncotarget. 2016; 7:1486-1499. doi: 10.18632/oncotarget.6429.

40. Duchnowska R, Peksa R, Radecka B, Mandat T, Trojanowski T, Jarosz B, Czartoryska-Arlukowicz B, Olszewski WP, Och W, Kalinka-Warzocha E, Kozlowski W, Kowalczyk A, Loi S, et al. Immune response in breast cancer brain metastases and their microenvironment: the role of the PD-1/PD-L axis. Breast Cancer Res. 2016; 18:43.

41. Bates GJ, Fox SB, Han C, Leek RD, Garcia JF, Harris AL, Banham AH. Quantification of regulatory T cells enables the identification of high-risk breast cancer patients and those at risk of late relapse. J Clin Oncol. 2006; 24:5373-5380.

42. Curiel TJ, Coukos G, Zou L, Alvarez X, Cheng P, Mottram P, Evdemon-Hogan M, Conejo-Garcia JR, Zhang L, Burow M, Zhu Y, Wei S, Kryczek I, et al. Specific recruitment of regulatory $\mathrm{T}$ cells in ovarian carcinoma fosters immune privilege and predicts reduced survival. Nat Med. 2004; 10:942-949.

43. Sasada T, Kimura M, Yoshida Y, Kanai M, Takabayashi A. CD4+CD25+ regulatory $\mathrm{T}$ cells in patients with gastrointestinal malignancies: possible involvement of regulatory $\mathrm{T}$ cells in disease progression. Cancer. 2003; 98:1089-1099.

44. Sato E, Olson SH, Ahn J, Bundy B, Nishikawa H, Qian F, Jungbluth AA, Frosina D, Gnjatic S, Ambrosone C, Kepner J, Odunsi T, Ritter G, et al. Intraepithelial CD8+ tumor-infiltrating lymphocytes and a high CD8+/regulatory $\mathrm{T}$ cell ratio are associated with favorable prognosis in ovarian cancer. Proc Natl Acad Sci U S A. 2005; 102:18538-18543.

45. Ostrand-Rosenberg S, Sinha P, Beury DW, Clements VK. Cross-talk between myeloid-derived suppressor cells (MDSC), macrophages, and dendritic cells enhances tumorinduced immune suppression. Semin Cancer Biol. 2012; 22:275-281.

46. Yoshikawa K, Mitsunaga S, Kinoshita T, Konishi M, Takahashi S, Gotohda N, Kato Y, Aizawa M, Ochiai A. 
Impact of tumor-associated macrophages on invasive ductal carcinoma of the pancreas head. Cancer Sci. 2012; 103:2012-2020.

47. Komohara Y, Ohnishi K, Kuratsu J, Takeya M. Possible involvement of the M2 anti-inflammatory macrophage phenotype in growth of human gliomas. J Pathol. 2008; 216:15-24.

48. Ohtaki Y, Ishii G, Nagai K, Ashimine S, Kuwata T, Hishida T, Nishimura M, Yoshida J, Takeyoshi I, Ochiai A. Stromal macrophage expressing CD204 is associated with tumor aggressiveness in lung adenocarcinoma. $\mathrm{J}$ Thorac Oncol. 2010; 5:1507-1515.

49. Jinushi M, Komohara Y. Tumor-associated macrophages as an emerging target against tumors: Creating a new path from bench to bedside. Biochim Biophys Acta. 2015; 1855:123-130.

50. Ostuni R, Kratochvill F, Murray PJ, Natoli G. Macrophages and cancer: from mechanisms to therapeutic implications. Trends Immunol. 2015; 36:229-239.

51. Haas M, Dimmler A, Hohenberger W, Grabenbauer GG, Niedobitek G, Distel LV. Stromal regulatory T-cells are associated with a favourable prognosis in gastric cancer of the cardia. BMC Gastroenterol. 2009; 9:65.

52. Kayser G, Schulte-Uentrop L, Sienel W, Werner M, Fisch P, Passlick B, Zur Hausen A, Stremmel C. Stromal CD4/CD25 positive T-cells are a strong and independent prognostic factor in non-small cell lung cancer patients, especially with adenocarcinomas. Lung Cancer. 2012; 76:445-451.

53. Yoon HH, Orrock JM, Foster NR, Sargent DJ, Smyrk TC, Sinicrope FA. Prognostic impact of FoxP3+ regulatory T cells in relation to $\mathrm{CD} 8+\mathrm{T}$ lymphocyte density in human colon carcinomas. PLoS One. 2012; 7:e42274.

54. Tumeh PC, Harview CL, Yearley JH, Shintaku IP, Taylor EJ, Robert L, Chmielowski B, Spasic M, Henry G, Ciobanu V, West AN, Carmona M, Kivork C, et al. PD-1 blockade induces responses by inhibiting adaptive immune resistance. Nature. 2014; 515:568-571.

55. Sobin LH, Gospodarowicz M, Wittekind C. TNM classification of malignant tumors. 7th ed. New York: Wiley-Blackwell. 2009:66-72. 